\section{Commentary: Protecting lung transplant allografts by improving esophageal motility: Selecting the right patients}

\author{
Michael K. Y. Hsin, MD, FRCS(CTh), ${ }^{\text {a }}$ and \\ Simon Y. K. Law, PhD, MS, FRCSEd ${ }^{b}$
}

Gastroesophageal reflux disease (GERD) may lead to chronic allograft dysfunction after lung transplantation (LTx), and fundoplication has been shown to delay chronic allograft dysfunction in selected LTx recipients with GERD. ${ }^{1,2}$

Masuda and colleagues from St Joseph's Hospital and Medical Center in Phoenix, Ariz, ${ }^{3}$ previously reported the influence of LTx on foregut function, and showed that esophageal motility and reflux parameters varied significantly between patients with obstructive lung disease compared with those with restrictive lung disease. By restoring pulmonary physiology, LTx ameliorated the effects of end-stage lung disease on esophageal dysmotility and reflux. ${ }^{3}$

The same group also studied patients with aperistaltic esophagus, which is considered a relative contraindication for LTx by some centers. Aperistalsis impairs esophageal clearance and contributes to GERD and responds poorly to fundoplication. In patients with aperistaltic esophagus whose esophageal function improved after LTx, the 5-year survival after LTx was the same as the control group without aperistalsis. In those whose esophageal motility did not improve, the survival was much worse. In two-thirds of patients with aperistaltic esophagus, the esophageal function improved after LTx-therefore this finding is not necessarily a contraindication to LTx. Identification of pre-LTx features that are associated with post-

\footnotetext{
From the ${ }^{\mathrm{a} D e p a r t m e n t}$ of Cardiothoracic Surgery, Queen Mary Hospital, Hong Kong, SAR China; and ${ }^{\mathrm{b}}$ Department of Surgery, The University of Hong Kong, Hong Kong, SAR China.

Disclosures: The authors reported no conflicts of interest.

The Journal policy requires editors and reviewers to disclose conflicts of interest and to decline handling or reviewing manuscripts for which they may have a conflict of interest. The editors and reviewers of this article have no conflicts of interest.

Received for publication Jan 12, 2021; revisions received Jan 12, 2021; accepted for publication Jan 12, 2021; available ahead of print Jan 20, 2021.

Address for reprints: Michael K. Y. Hsin, MD, FRCS(CTh), Department of Cardiothoracic Surgery, Room 308, New Clinical Building, Queen Mary Hospital,

Hong Kong, SAR China (E-mail: mkhsin@hotmail.com).

J Thorac Cardiovasc Surg 2022;163:1987-8

$0022-5223 / \$ 36.00$

Copyright (c) 2021 by The American Association for Thoracic Surgery

https://doi.org/10.1016/j.jtcvs.2021.01.043
}

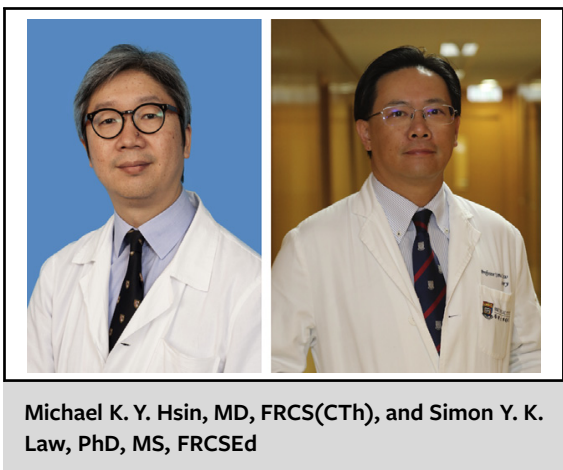

CENTRAL MESSAGE

PEA in lung transplant recipients
results in poor survival. Restric-
tive lung disease and sclero-
derma are associated with PEA.
Predictors of PEA may improve
patient selection.

LTx improved esophageal function may help patient selection. ${ }^{4}$

Giulini and colleagues ${ }^{5}$ studied LTx recipients who had preoperative esophageal aperistalsis on high-resolution manometry (HRM). Preoperative barium esophagography was used to assign scores to motility and dilation patterns. Using post-LTx HRM, patients were classified into those who had persistent esophageal aperistalsis post-LTx and those who had improved esophageal motility. ${ }^{5}$ They found that all patients with obstructive lung disease or pulmonary arterial hypertension had improved motility after LTx. However, only $50 \%$ improved among patients with restrictive lung disease. Furthermore, among patients with connective tissue disorder, all those with diffuse systemic sclerosis had persistent aperistalsis after LTx. In 1 patient with rheumatoid arthritis and another with systemic sclerosis sine scleroderma, both had improved peristalsis after LTx. The authors suggest that patients with obstructive lung disease or pulmonary artery hypertension tended to do well, whereas diffuse systemic sclerosis should be considered a contraindication for LTx.

This study provides useful insight into the pathophysiology of esophageal dysfunction in patients undergoing LTx, and may help refine selection for LTx candidacy. Nevertheless, there are important limitations. First, only 29 patients with esophageal aperistalsis were seen over 4 years, and only 4 patients had systemic sclerosis. Clearly 
these findings need to be further verified with a larger cohort. Second, their interpretation of barium esophagrams involved subjective scores of motility and dilation patterns. It is important to validate this methodology.

The gold standard to evaluate esophageal motility still relies on HRM. The authors used distal contractile integral combined with percent of normal, weak, or failed swallows as parameters for persistent esophageal aperistalsis or improved motility. How this classification really relates to postoperative function and how it correlates with graft survival requires more patients for validation. Novel methods to evaluate esophageal function, such as the EndoFlip Impedance Planimetry system 2.0 (Medtronic, Minneapolis, Minn), may be worth exploring in the future. ${ }^{6}$

\section{References}

1. D'Ovidio F, Mura M, Tsang M, Waddell TK, Hutcheon MA, Singer LG, et al. Bile acid aspiration and the development of bronchiolitis obliterans after lung transplantation. J Thorac Cardiovasc Surg. 2005;129:1144-52.

2. Biswas Roy S, Elnahas S, Serrone R, Haworth C, Olson MT, Kang P, et al. Early fundoplication is associated with slower decline in lung function after lung transplantation in patients with gastroesophageal reflux disease. J Thorac Cardiovasc Surg. 2018;155:2762-71.e1.

3. Masuda T, Mittal S, Kovasc B, Smith MA, Walia R, Huang JL, et al. Foregut function before and after lung transplant. J Thorac Cardiovasc Surg. 2019;158:619-29.

4. Masuda T, Mittal S, Csucska M, Kovacs B, Walia R, Huang JL, et al. Esophageal aperistalsis and lung transplant: recovery of peristalsis after transplant is associated with improved long-term outcomes. J Thorac Cardiovasc Surg. 2020;160:1613-26.

5. Giulini L, Mittal SK, Masuda T, Razia D, Csucska M, Walia R, et al. Factors associated with esophageal motility improvement after bilateral lung transplant in patients with an aperistaltic esophagus. J Thorac Cardiovasc Surg. 2022;163:1979-86.

6. Desprez C, Roman S, Leroi AM, Gourcerol G. The use of impedance planimetry (endoscopic functional lumen imaging probe, EndoFLIP ${ }^{\circledR}$ ) in the gastrointestinal tract: a systematic review. Neurogastroenterol Motil. 2020;32:e13980.
See Article page 1979.

\section{Commentary: To know yourself is to know your neighbor}

\author{
Keita Nakanishi, MD, and \\ Toyofumi Fengshi Chen-Yoshikawa, MD
}

Lung transplantation (LTx) is the final treatment for patients with end-stage lung disease with severe respiratory failure. However, the prognosis after LTx is worse than that after other solid organ transplantations, mainly because of chronic lung allograft dysfunction. ${ }^{1}$ Impaired esophageal motility has been identified as a post-LTx risk factor for chronic lung allograft dysfunction. ${ }^{2}$ Previously, Masuda and colleagues, ${ }^{3}$ supervised by Dr Bremner, demonstrated that esophageal motility could improve after LTx even in patients with esophageal aperistalsis. In addition, they also reported that the patients with improved esophageal

\footnotetext{
From the Department of Thoracic Surgery, Nagoya University Graduate School of Medicine, Nagoya, Japan.

Disclosures: The authors reported no conflicts of interest.

The Journal policy requires editors and reviewers to disclose conflicts of interest and to decline handling or reviewing manuscripts for which they may have a conflict of interest. The editors and reviewers of this article have no conflicts of interest.

Received for publication Jan 8, 2021; revisions received Jan 8, 2021; accepted for publication Jan 8, 2021; available ahead of print Jan 20, 2021.

Address for reprints: Toyofumi Fengshi Chen-Yoshikawa, MD, Department of Thoracic Surgery, Nagoya University Graduate School of Medicine, 65 Tsurumai-cho, Showa-ku, Nagoya, 466-8550 Japan (E-mail: tyoshikawa@med. nagoya-u.ac.jp).

J Thorac Cardiovasc Surg 2022;163:1988-9

$0022-5223 / \$ 36.00$

Copyright (c) 2021 by The American Association for Thoracic Surgery

https://doi.org/10.1016/j.jtcvs.2021.01.030
}

Check for updates

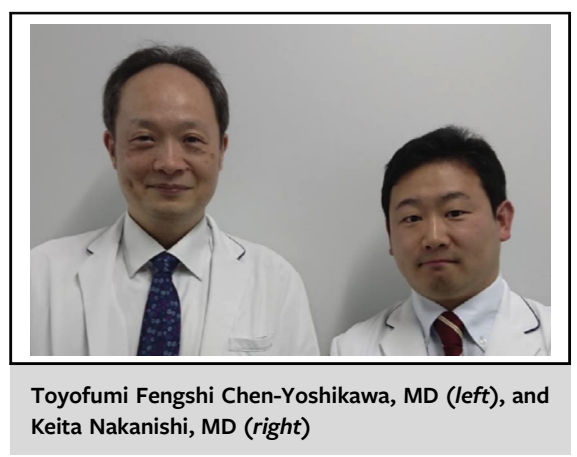

CENTRAL MESSAGE

The combination of type of primary lung disease and results of barium esophagography might better predict improved esophageal motility after lung transplant in patients with an aperistaltic esophagus.

peristalsis (IEP) had long-term survival rates comparable to patients with normal preoperative peristalsis. ${ }^{4}$ For the next step, it is important to determine which LTx candidates who have aperistalsis are most likely to acquire IEP after LTx.

In their recent study, Giulini and colleagues ${ }^{5}$ focus on 29 patients with complete aperistalsis and investigate factors associated with IEP, as well as risk factors for persistent 